\title{
Proceeding
}

6th INSHS International Christmas Sport Scientific Conference, 11-14 December 2011. International Network of Sport and Health Science. Szombathely, Hungary

\section{Eating behaviors and physical activity in Albanians $9-11$ years ald children}

\author{
ROBERT ÇITOZI , GENTI PANO
}

Department of Physical Activity Recreation and Tourism, Faculty of Physical Activity and Recreation, Sport Sciences Research Institute, University of Sport of Tirana, Albania

\begin{abstract}
Çitozi R, Pano G. Eating behaviors and physical activity in Albanians 9-11 years ald children. J. Hum. Sport Exerc. Vol. 7, No. Proc1, pp. S154-S165, 2012. As most research about preferences has ignored cognitive development, this study was designed to explore the relation between children's perceptions and preferences for fruit and vegetables and their physical activity. 210 children (100-boys and 110-girls) 9-11 years old recruited via a primary school from Tirana, have fulfilled the questionnaire. This questionnaire has proved to be very interesting for the children who are expected to be very satisfied with its successful completion. Analysis of data collected made us a clearer picture on the extent of informing children about the role of fruit and vegetables in their health and on their conception of the physical activity. It is not always possible to control genetic and environmental factors, but at least by making conscious nutritional habits beginning from childhood, we can make a strong effect on our health, happiness and the quality, length and productivity of our life. Participation in the school meal programs should be the strongest positive relationship with fruit and vegetable consumption and meeting the 5 a Day recommendation. Expand the promotion of 60 daily minutes of a combination of moderate and vigorous physical activity among children. Key words: FRUITS, VEGETABLES, OBESITY, CHILDREN, PHYSICAL ACTIVITY.
\end{abstract}

\footnotetext{
Corresponding author. Department of Physical Activity Recreation and Tourism, Faculty of Physical Activity and Recreation, Sport Sciences Research Institute, University of Sport of Tirana, Albania.

E-mail: rcitozi@yahoo.com 6th INSHS International Christmas Sport Scientific Conference, 11-14 December 2011. International Network of Sport and Health Science. Szombathely, Hungary JOURNAL OF HUMAN SPORT \& EXERCISE ISSN 1988-5202

(C) Faculty of Education. University of Alicante doi:10.4100/jhse.2012.7.Proc1.17
} 


\section{INTRODUCTION}

Most children do not meet the recommended guidelines for fruit and vegetable intake. Since preference is an important predictor of intake, more knowledge is needed about children's preferences and about how these preferences develop. As most research about preferences has ignored cognitive development, this study was designed to explore the relation between children's perceptions and preferences for fruit and vegetables (Gertrude et al., 2007) and their physical activity. A lack of physical activity and poor dietary habits are believed to be the major contributors to the current rise in childhood obesity. (Butland et al., 2007). Both behaviours have also been shown to have independent associations with other health problems during childhood, including metabolic impairments (Ekelund at al., 2007) and poor skeletal health (Hind K \& Burrows M., 2006). Increasing physical activity and improving dietary habits in childhood have therefore been identified as targets for future public health policy (Butland et al., 2007).

Previous studies have reported mixed results, with the proportion of children achieving the recommended guideline of at least one hour of moderate-to-vigorous intensity physical activity (MVPA) each day (London Department of Health., 2004). However, most studies indicate that physical activity levels decline with age, especially during late primary school years and throughout secondary school (Sallis et al., 2000), making this a potentially important period for health promotion interventions. Although there is some information available on the nutritional content of the diet of primary school-aged children (Glynn at al., 2005), little is known about their dietary behavior such as food choice.

Ministry of Health of Albania recommendations for 4-12-year-old children of 150 grams of vegetables and two pieces $₹ 200 \mathrm{gram}$ ) of fruit, are in line with i nternational guidelines (WHO WHO Technical Report Series 916 (Geneva, 2003). Because food preferences and eating habits established in childhood often persist into adulthood, children are an appropriate group to target in order to positively influence dietary habits (Nicklaus et al., 2004). In recent years, several studies and programs have been set up to increase fruit and vegetable intake in children (Blanchette \& Brug, 2005). Positive changes have been found in knowledge, self-efficacy, skills, awareness, liking and intake.

\section{MATERIAL AND METHODS}

We have used (Baranowski, Davis, Resnicow, Baranowski, Doyle, Smith, et al., 2000) questionnaire. 210 children (100-boys and 110-girls) 9-11 years old recruited via a primary school from Tirana, have fulfilled the questionnaire. Target behavior is fruit and vegetable consumption and physical activity.

This survey includes scales that measure:

1. Children's knowledge about fruit and vegetables

2. Positive outcome expectations for eating fruit and vegetables

3. Self-efficacy in asking, and shopping for fruit and vegetables

4. Self-efficacy for eating fruit and vegetables

5. Children's knowledge about physical activity 
6. Outcome expectations for the physical outcomes of engaging in physical activity

7. Self-efficacy for engaging in physical activity

After selecting the scales, the instrument was pilot tested with the target audience, reduced in length, and finalized. The length of the survey was limited in size and scope to keep children actively engaged. The final instrument was designed to be easily conducted by teachers with brief written instructions on survey administration. Positive fruit and vegetable outcome expectations (9 items) measured responses on a 5point like scale ranging from 1 (disagree very much) to 5 (agree very much). Fruit and vegetable selfefficacy was drawn from a 22-question instrument provided by Baranowski and colleagues (2004). After deleting items with no relevance to the intervention, the asking and shopping self-efficacy measure equaled 8 items, and eating self-efficacy was reduced to 3 questions. Both scales used the same 5 response options outlined above. The physical activity outcome expectations were measured by 7 items. The original scale was reduced by three questions and one item that did not relate to the intervention was dropped. Physical activity support seeking self-efficacy was also measured by 7 items and physical activity barriers self-efficacy by 4 items. All three measures used "yes" and "no" response categories.

\section{RESULTS}

This questionnaire has proved to be very interesting for the children who are expected to be very satisfied with its successful completion. Instruct teachers in advance made us more easily to meet the exact and the seriousness of the children for all components and details of the questionnaire. Analysis of data collected made us a clearer picture on the extent of informing children about the role of fruit and vegetables in their health and on their conception of the physical activity.

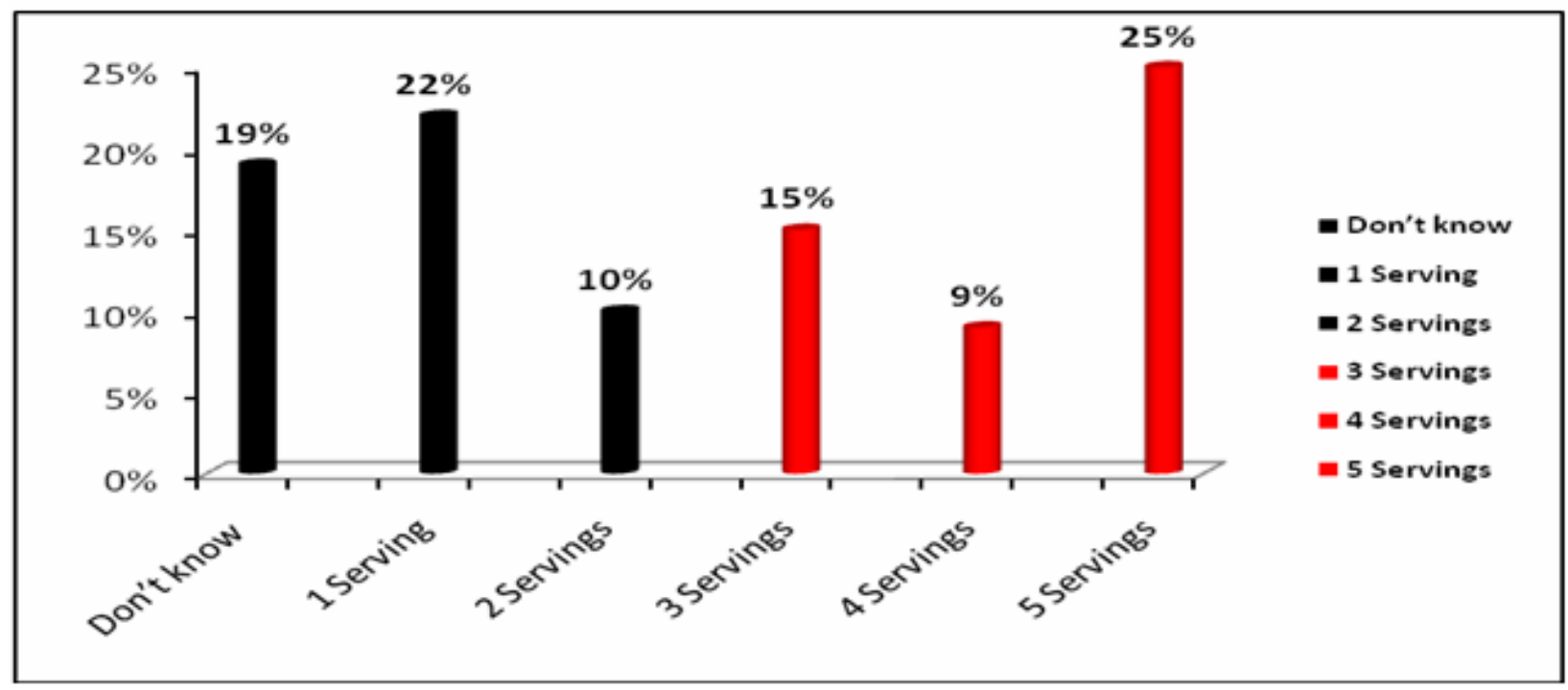

Figure 1. Children's knowledge about fruit and vegetables. 
Figure 1 shows that if the recommendations for fruit and vegetable consumption are 3-5 servings a day, about $19 \%$ of children responded: I do not know, 22\%- 1 serving, 10\%- 2 servings, $15 \%-3$ servings, $9 \%$ - 4 servings and $25 \%-5$ servings. We have calculated the average of responses both fruit and vegetables, but if we present separate, the response level for vegetables is weaker than fruits that shows that fruits are more attractive for the children.

The information level for the girls of this age is better than boys, but when about $51 \%$ of children are not adequately informed on the recommendations of the fruit and vegetable consumption 3 to 5 cups of fruits, (Network for a Healthy California Children's Power Play Campaign), that give more responsibility for all structures that have a role in securing and organizing a healthy life in general and in particular for the children of this age.

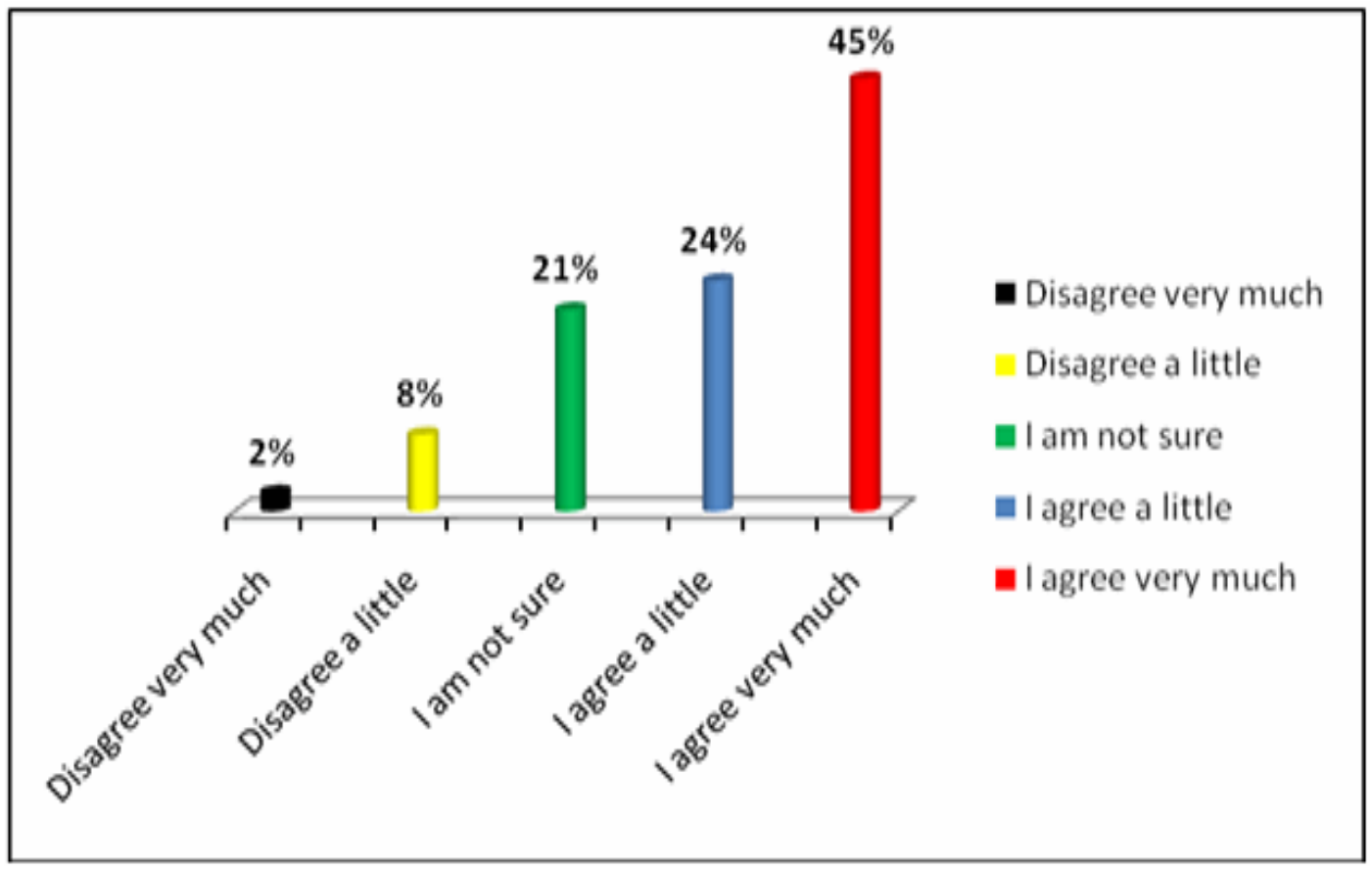

Figure 2. Positive outcome expectations for eating fruit and vegetables.

In Figure 2 it is clear that we should be pleased because about $69 \%$ of children have been answered, I agree a little or I agree very much, while the negative is $2 \%+8 \%=10 \%$. The result of this table shows that children have positive outcome expectations for eating fruit and vegetables. 
Table 1. Total results of session 3-4. Self-efficacy in asking, and shopping for fruit and vegetables. (A-1 point, B-2 points, C-3 points, D-4 points, E-5 points (see Baranowski, 2000).

\begin{tabular}{|c|c|c|c|c|c|}
\hline \multicolumn{6}{|c|}{ Self-efficacy in asking, and shopping for fruit and vegetables } \\
\hline $\begin{array}{l}\text { 14. I think i can write my favorite } \\
\text { fruit or vegetable on the family's } \\
\text { shopping list }\end{array}$ & A-30\% & B- $10 \%$ & $\mathrm{C}-\mathbf{5} \%$ & D-15\% & E-40\% \\
\hline $\begin{array}{l}\text { 15. I think I can ask someone in my } \\
\text { family to buy my favorite fruit or } \\
\text { vegetable }\end{array}$ & A-20\% & B-5\% & $\mathrm{C}-8 \%$ & D-17\% & $\mathbf{E}-\mathbf{5 0} \%$ \\
\hline $\begin{array}{l}\text { 16. I think I can go shopping with my } \\
\text { family for my favorite fruit or } \\
\text { vegetable }\end{array}$ & A-10\% & B-3\% & $\mathrm{C}-7 \%$ & D-24\% & $\mathrm{E}-56 \%$ \\
\hline $\begin{array}{l}\text { 17. I think I can pick out my favorite } \\
\text { fruit or vegetable at the store and put } \\
\text { it in the shopping basket }\end{array}$ & A- $7 \%$ & B-3\% & $\mathrm{C}-10 \%$ & D- $15 \%$ & E-65\% \\
\hline Average in $\%$ & A-16.75\% & B-5.25\% & $\mathrm{C}-7.5 \%$ & D-17.75\% & E-52.75\% \\
\hline
\end{tabular}

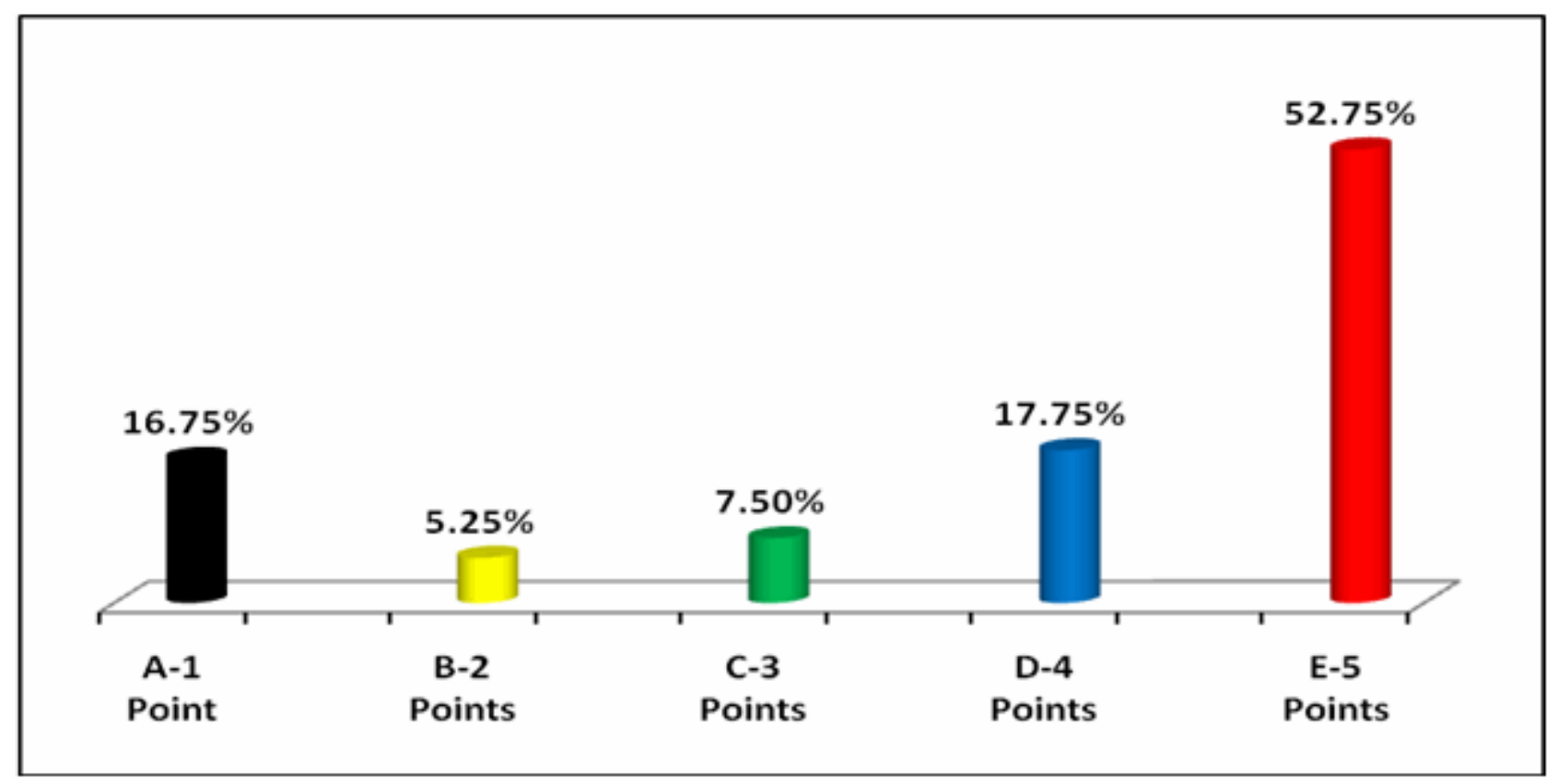

Figure 3. Total results of session 3-4. 
Results of the average value in this table are optimistic and show that the answer 17 , about $65 \%$ of children prefer to pick out the favourite fruit or vegetable at the store and put it in the shopping basket. Only $16.75 \%$ of children responded: I disagree very much, and $5.25 \%$ I disagree a little, which gives a message to parents to take always their children with them, when they go shopping, because the children prefer to choose their favourite fruits and vegetables. This affects not only the choice of children for fruits or vegetables that they prefer, but an active time spent with parents is very useful for educating children about a feeling of family to join them

Table 2. Total results of session 3-4/B. Self-efficacy for eating fruit and vegetables. (A-1 point, B-2 points, C-3 points, D-4 points, E-5 points).

\begin{tabular}{|c|c|c|c|c|c|}
\hline \multicolumn{6}{|c|}{ Self-efficacy for eating fruit and vegetables } \\
\hline $\begin{array}{l}\text { 18. I think } \mathrm{i} \text { can ask someone in my } \\
\text { family to make my favorite vegetable } \\
\text { dish for dinner }\end{array}$ & A-28\% & B-10\% & $\mathrm{C}-16 \%$ & D-20\% & E-26\% \\
\hline $\begin{array}{l}\text { 19. I think } \mathrm{i} \text { can ask someone in my } \\
\text { family to serve my favorite fruit at } \\
\text { dinner }\end{array}$ & A-36\% & B-8\% & $\mathrm{C}-14 \%$ & D-21\% & E-21\% \\
\hline $\begin{array}{l}\text { 20. I think } \mathrm{i} \text { can ask someone in my } \\
\text { family to have fruits and fruit juices } \\
\text { out where } \mathrm{i} \text { can reach them }\end{array}$ & A-25\% & B-11\% & $\mathrm{C}-17 \%$ & D-24\% & $\mathbf{E}-\mathbf{2 3} \%$ \\
\hline $\begin{array}{l}\text { 21. I think } i \text { can ask someone in my } \\
\text { family to have cut up vegetables out } \\
\text { where } i \text { can reach them }\end{array}$ & A-38\% & B $-8 \%$ & $\mathrm{C}-10 \%$ & D-20\% & E-24\% \\
\hline $\begin{array}{l}22 \text {. I think } \mathrm{i} \text { can eat } 2 \text { or more } \\
\text { servings of fruit or fruit juice each } \\
\text { day }\end{array}$ & A-18\% & B-20\% & $\mathrm{C}-15 \%$ & D-34\% & E-13\% \\
\hline $\begin{array}{l}\text { 23. I think } \mathrm{i} \text { can eat } 3 \text { or more } \\
\text { servings of vegetables each day }\end{array}$ & A-26\% & B-13\% & $\mathrm{C}-18 \%$ & D-27\% & E-16\% \\
\hline $\begin{array}{l}\text { 24. I think } i \text { can eat } 5 \text { or more } \\
\text { servings of fruits and vegetables each } \\
\text { day }\end{array}$ & A-17\% & B-17\% & $\mathrm{C}-14 \%$ & D-29\% & E-23\% \\
\hline Average in $\%$ & A-26.85\% & B-12.4\% & C-14.85\% & D-25\% & E-20.85\% \\
\hline
\end{tabular}




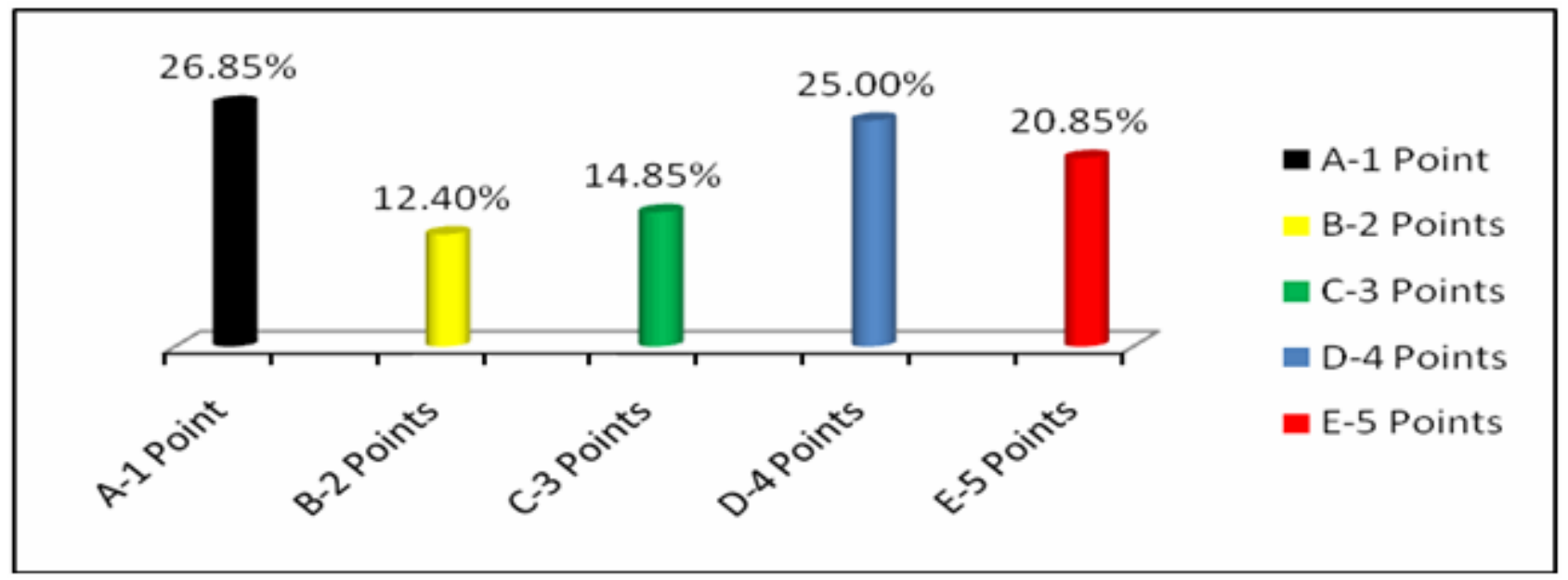

Figure 4. Total results of session 3-4/B.

The data in this table shows us that only $D+E=45.85 \%$ of children have a good self-efficacy for eating fruit and vegetables, while the rest $A+B+C=54.15 \%$ are in marginal or moderate level which shows that they are very dependent upon their parents, while responses $22,23,24$ are almost on par with the responses in Figure.1

Table 3. Children's knowledge about physical activity.

PHYSICAL ACTIVITY Please choose your answer.

25. How many minutes of physical activity do you think elementary school students should get each day to be healthy?
A. At least 15 minutes each day- $17 \%$
B. At least 30 minutes each day- $19 \%$
C. At least 60 minutes each day- $27 \%$
D. At least 90 minutes each day- $16 \%$

\section{E. Don't know- $21 \%$}

26 Why is physical activity good for kids?
A. Helps keep you from getting sick- $1 \%$
B. Helps you pay attention in school- $0 \%$
C. Builds healthy bones and muscles to keep you strong- $0 \%$
D. Gives you more energy- $\mathbf{3} \%$
E. All of the above- $96 \%$ 
In this table by reference to the recommendation for children of this age became physically active for at least 60 minutes every day (Network for a Healthy California- Children Power Play Campaign), we see that only $27 \%$-answered correctly, 21\% -Don't now, 17\% -At least 15 minutes, 19\% -At least 30 minutes, 16\% At least 90 minutes. When completing this section of the questionnaire, from the reaction of the children we have seen that they had no information from either teachers or parents about this problem. Question 26/E responded positively to $96 \%$ of the children that is for us a satisfactory indicator of the extent of informing children about the values of physical activity for their health.

Table.4 Outcome expectations for the physical outcomes of engaging in physical activity

\begin{tabular}{|c|c|c|}
\hline PHYSICAL ACTIVITY (I THINK) & iswer. & \\
\hline & No & Yes \\
\hline 27. I think i can be physically active most days after school & $35 \%$ & $65 \%$ \\
\hline $\begin{array}{l}\text { 28. I think } i \text { can ask my parent or other adult to do physically active } \\
\text { things with me }\end{array}$ & $60 \%$ & $40 \%$ \\
\hline $\begin{array}{l}\text { 29. I think i can ask my parent or other adult to sign me up for a } \\
\text { sport, dance, or other physical activity }\end{array}$ & $48 \%$ & $52 \%$ \\
\hline $\begin{array}{l}\text { 30. I think i can be physically active even if it is very hot or cold } \\
\text { outside }\end{array}$ & $61 \%$ & $39 \%$ \\
\hline 31. I think i can ask my best friend to be physically active with me & $18 \%$ & $82 \%$ \\
\hline $\begin{array}{l}\text { 32. I think } i \text { can ask my parent or other adult to get me the equipment } \\
\text { i need to be physically active. }\end{array}$ & $36 \%$ & $64 \%$ \\
\hline $\begin{array}{l}\text { 33. I think i can ask my parent or other adult to take me to a physical } \\
\text { activity or sport practice }\end{array}$ & $52 \%$ & $48 \%$ \\
\hline 34. I think $i$ can be physically active even if $i$ have a lot of homework & $61 \%$ & $39 \%$ \\
\hline 35. I think i have the skills i need to be physically active & $17 \%$ & $83 \%$ \\
\hline 36. I think $i$ can be physically active no matter how busy my day is & $58 \%$ & $42 \%$ \\
\hline 37 I think i can be physically active no matter how tired i may feel & $64 \%$ & $36 \%$ \\
\hline Average & $44.60 \%$ & $55.40 \%$ \\
\hline
\end{tabular}


From the responses of Table 4, we can see very interesting conclusions. At first it appears that $55.4 \%$ of children are willing to be active and involved in physical activity. In answer $\mathrm{Nr}-28$, we see that $60 \%$ of children do not want to go with parents in sport or physical activity, but when it comes to the best friend, $82 \%$ of them want to be together with their closed friend in physical activity and sport. When outside it is cold or warm, or when they have more homework or are busy, appears that $61 \%$ of them will not deal with physical activity, which means that children are pampered and less spirit of sacrifice. The answer 35 , shows that $83 \%$ of them believe in their abilities to be active plum referred confidence or self-esteem.

Table 5. Self-efficacy for engaging in physical activity.

\begin{tabular}{|l|c|c|}
\hline PHYSICAL ACTIVITY (IT WOULD) & \multicolumn{3}{|c|}{ Please choose your answer. } \\
\hline If i were to be physically active most days... & No & Yes \\
\hline 38 it would help me be healthy & $12 \%$ & $88 \%$ \\
\hline 39. it would help me control my weight & $39 \%$ & $61 \%$ \\
\hline 40. it would make me embarrassed in front of others & $81 \%$ & $19 \%$ \\
\hline 41. it would be fun & $17 \%$ & $83 \%$ \\
\hline 42. it would get or keep me in shape & $11 \%$ & $89 \%$ \\
\hline 43. it would be boring & $\mathbf{8 6} \%$ & $14 \%$ \\
\hline 44. it would make me better in sports & $\mathbf{2 5} \%$ & $75 \%$ \\
\hline
\end{tabular}

In Table 5 responses, generally we have a good self-efficacy for engaging in physical activity by children. I think, today and in the future it should have more information on the contribution of physical activity in weight control, because knowing the 21-century world's greatest problem of obesity, $39 \%$ of them turns out to have no information in this regard (Ref. Answer. 39). In order to preserve our weight we must get a balanced and healthy nutrition, exercise and be careful about not having a sedentary life style. Having an active and sportive way of life is important for our heart-vessel and bone health.

\section{DISCUSSION}

Nutrition is one of the most important factors in protecting and developing human health beginning from the pregnancy stage of the mother. Healthy, satisfactory and balanced nutrition is essential for everybody, especially for children, because nutritional habits that are made in our early ages turn out to be our lifetime habits. Infancy, childhood and adolescence periods, as being periods of rapid growth and development, are important stages for the making of good, healthy and satisfactory nutritional habits. Growth and development is deeply related with various factors like nutrition, genetic structure, gender, environment, socio-economic position, culture and traditions. It is not always possible to control genetic and environmental factors, but at least by making conscious nutritional habits beginning from childhood, we can make a strong effect on our health, happiness and the quality, length and productivity of our life. 
"While healthy nutrition is the basis of healthy childhood, healthy childhood in its turn is the basis of healthy life" (Karaagaoglu, 2006). Many factors influence children's eating, including their parents and family members, their friends, educational institutions and the mass media, especially television. Like most adults, most children do as their peers, (Birch, 1999) showed that the food consumption of toddlers and primary and secondary school children is influenced by the social groups to which they belong. If we are to influence children's eating, therefore, we should try to influence these groups, as well as appeal to the children directly. This approach has several implications.

The ways in which parents consume food will influence their children (Hursti, 1999). If the parents do not eat fruit, for example, then the children will be unlikely to do so. Interventions should aim, therefore, to influence parents' habits because parents are the gatekeepers for much of the food entering the family (Campbell \& Crawford., 2001). This means the messages of any intervention program have to appeal to parents, who must find any changes worthwhile for themselves as well as their children. We have to started a multi-strategic health promotion program aimed at increasing fruit and vegetable consumption among primary school children in our country by improving:

- Children's fruit and vegetable knowledge, attitudes, access and preparation skills.

- Parents' fruit and vegetable knowledge and preparation skills and their involvement in fruit and vegetable promoting activities in the schools and elsewhere.

- Teachers' attitudes towards teaching about fruits and vegetables in schools and their skills and confidence in relation to teaching about fruits and vegetables.

From a health perspective, there are three main rationales for encouraging 9-11 years old children to take part in regular physical activity: to optimize physical fitness, current health and well-being, and growth and development, to develop active lifestyles that can be maintained throughout adult life and to reduce the risk of chronic diseases of adulthood (Biddle et al., 1998). A positive attitude towards physical activity and adoption of a physically active lifestyle are important components of preventive medicine that should begin in childhood. (Medical aspects of exercise: benefits and risks. Summary of a report of the Royal College of Physicians. J R Coll Physicians Lond, (1991). Both physical activity and physical inactivity have a tendency to track into adulthood and it is important to establish healthy activity habits while young.

1. Children who are physically active are less likely to be overweight (Berkey et al., 2000).

2. Children who engage in weight-bearing activities have greater bone density and better skeletal health in both the short- and long-term (Bailey et al., 1999).

3. Physically active children are more likely to have a higher level of self-esteem, more positive body image, and lower levels of stress and anxiety (Alfermann et al., 2000).

4. Learning by doing at an early age is fundamental to the quality of skill acquisition. The best time to begin teaching motor skills fundamental to a physically active lifestyle is in the pre-primary and primary years, especially in the 'years of readiness' at age 5-6 years (Blanksby et al., 1995). 


\section{CONCLUSIONS}

Participation in the school meal programs should be the strongest positive relationship with fruit and vegetable consumption and meeting the 5 a Day recommendation. Therefore, intervention efforts aimed at improving school meal program participation could dramatically improve fruit and vegetable intake among children. We have to promote participation in the school breakfast and school lunch programs. However, for most children, breakfast and snack times were marked by relatively low fruit and vegetable consumption making these eating occasion prime targets for improvement. Children with the knowledge and skills to make healthful fruit and vegetable choices are better equipped to choose, prepare, and eat fruits and vegetables. We have to promote 60 Minutes of Daily Physical Activity. Very few children knew the amount of physical activity recommended for good health. In fact, less than 27 percent correctly reported 60 minutes per day. This is a key area for improvement in future intervention efforts. Fully integrate physical activity into intervention activities and materials. Expand the promotion of 60 daily minutes of a combination of moderate and vigorous physical activity among children. Encourage school and community organization partnerships to offer interventions that promote physical activity.

\section{REFERENCES}

1. ALFERMANN D, STOLL O. Effects of physical exercise on self-concept and wellbeing. International. Journal of Sport Psychology. 2000; 31(1):47-65.

2. BAILEY DA, MCKAY HA, MINWARD RI, CROCKER PRE, FAULKNER RA. A six-year longitudinal study of the relationship of physical activity to bone mineral accrual in young children: The University of Saskatchewan bone mineral accrual study. J Bone Miner Res. 1999; 14:1672-1679.

3. BARANOWSKI T, DAVIS M, RESNICOW K, BARANOWSKI J, DOYLE C, LIN L, SMITH M, WANG DT. Gimme 5 fruit, juice and vegetables for fun and health: outcome evaluation. Health Education and Behavior, 2000; 27:96-111.

4. BERKEY CS, ROCKETT HRH, FIELD AE, GILLMAN MW, FRAZIER AL, CAMARGO CA, COLDITZ GA. Activity, dietary intake, and weight changes in a longitudinal study of preadolescent and adolescent boys and girls. Pediatrics 2000; 105.

5. BIDDLE S, SALLIS J, CAVILL N. Young and Active? Young People and Health-enhancing Physical Activity - Evidence and Implications. London: Health Education Authority, 1998.

6. BIRCH LL. 'Development of food preference', Annual Review of Nutrition. 1999; 19:41-62.

7. BLANCEHETTE L, BRUG J. Determinants of fruit and vegetable consumption among 6-12-yearold children and effective interventions to increase consumption. Journal of Human Nutrition and Dietetics. 2005; 18:431-443.

8. BLANKSBY B, PARKER H, BRADLEY S, ONG V. Children's readiness for learning front crawl swimming. Aust J Sci Med Sport. 1995; 27:34-37.

9. BUTLAND B, JEBB SA, KOPELMAN P, MCPHERSON K, THOMAS S, MARDELL J, PARRY V. BMC Public Health. 2008; 8:388.

10. CAMPBELL K, CRAWFORD D. 'Family food environments as determinants of preschool aged children's eating behaviors: implications for obesity prevention policy-a review', Australian Journal of Nutrition and Dietetics. 2001; 58:19-25.

11. DEPARTAMENT OF HEALTH. At least five a week: evidence on the impact of physical activity and its relationship to health. London: Department of Health; 2004.

12. EKELUND U, ANDERSSEN SA, FROBERG K, SARDINHA LB, ANDERSSEN LB, BRAGE S. BMC Public Health; 2008.

13. GERTUDE GZ, MARIA AK, FRANS JK, CEES DE G. Int J Behav Nutr Phys Act. 2007; (4). 
14. GLYNN L, EMMETT P, ROGERS I. The ALSPAC Study Team: Food and nutrient intakes of a population sample of 7-year-old children in the south-west of England in 1999/2000-what difference does gender make? J Hum Nutr Diet 2005, 18:7-19.

15. HIND K, BURROWS M. Proc Nutr Soc. 2006; 65(4):348-360.

16. KACI R. Network for a Healthy California-Children's Power Play Campaign; 2005.

17. KOIVISTO H. Factors influencing children's food choice. Annals of Medicine. 1999; 1 (supplement): 26-32.

18. MEDICAL ASPECTS OF EXERCISE. Benefits and risks. Summary of a Report of the Royal College of Physicians. J R Coll Physicians Lond. 1991; 25(3):193-196.

19. NICKLAUS S, BOGGIO V, CHABANET C, ISSANCHOU S. A prospective study of food preferences in childhood. Food Qual Pref. 2004; 15:805-818.

20. SALLIS JF, PROCHASKA JJ, TAYLOR WC. A review of correlates of physical activity of children and adolescents. Medicine and Science in Sports and Exercise. 2000; 32(5):963-975 